\title{
Addendum: A breast cancer stem cell niche supported by juxtacrine signalling from monocytes and macrophages
}

\author{
Haihui Lu, Karl R. Clauser, Wai Leong Tam, Julia Fröse, Xin Ye, Elinor Ng Eaton, Ferenc Reinhardt, \\ Vera S. Donnenberg, Rohit Bhargava, Steven A. Carr and Robert A. Weinberg
}

Nat. Cell Biol. 16, 1105-1117; published online 28 September 2014; corrected online 27 November 2015

The MDA-MB-435 cell line used in Supplementary Fig. 2e-g is found on the list of commonly misidentified cell lines that is maintained by ICLAC and NCBI BioSample, where it is listed as a melanoma cell line misidentified as representing breast cancer. In this Article it was also misidentified and used as a breast cancer model. However, the use of this cell line does not affect the key findings of the paper, given that it was used to demonstrate that $\mathrm{CD} 90^{\text {hi }}$ cells are more tumorigenic than their $\mathrm{CD} 90^{\mathrm{lo}}$ counterparts, as a supporting piece of data in addition to characterizing the $\mathrm{CD} 90^{\mathrm{hi}}$ cell population in HMLE and HMLER (HMLE cells that had been transformed with the $H$-RasV12 oncogene) cells. 